\title{
THE VISCOELASTIC NATURE OF THE SLIDING FRICTION OF POLYETHYLENE, POLYPROPYLENE AND COPOLYMERS
}

\author{
S. BAHADUR \\ Iowa State University, Ames, Iowa (U.S.A.) \\ K. C. LUDEMA \\ The University of Michigan, Ann Arbor, Mich. (U.S.A.) \\ (Received February 23, 1971)
}

SUMMARY

According to the adhesion theory of sliding friction, the sliding force or frictional resistance to motion is due to making and breaking of adhesional bonds between the sliding bodies. Thus the sliding force $F$ is proportional to the shear strength $S$ of adhesional bonds and the area of contact $A$ between contacting bodies. This paper reports the results of a study to find the proper relationship between $F, A$ and $S$. The value of $F$ is taken from a friction test over a sliding speed range of 10,000 to 1 and over a temperature range up to $150^{\circ} \mathrm{C}$. The values of $A$ and $S$ are derived from shear tests, also over wide ranges of strain rate and temperature. All data were then subjected to special viscoelastic transformation. It was found that the friction data were transformable by the same transforms applicable to mechanical property data, provided changes in polymer morphology are taken into account. This coincidence is evidence of a strong connection between $A, S$ and $F$ which lends support to the adhesion theory of friction.

\section{INTRODUCTION}

It is often found that the coefficient of friction $\mu$ varies significantly when sliding speed or temperature is varied. This behavior was well demonstrated by Bueche and Flom $^{1}$ and by Grosch ${ }^{2}$. Typical results of such work are shown in Fig. 1 for glass on rubber; $\mu$ varies by more than $6: 1$ and exceeds unity. The latter possibility is often denied by engineers and scientists.

The fundamental cause of the variations in $\mu$ in Fig. 1 is as difficult to establish as the cause of friction. Serious speculation on this topic has been continuing for about 35 years. In recent years, the adhesion theory of friction of Bowden and Tabor $^{3}$ has gained the majority support, partly by experimental evidence for adhesion, but often by proof against competing theories. Modern discussion on the doubts about the adhesion theory of friction center on phenomena that may result from friction rather than be the cause of it.

The straightforward proof of the adhesion theory of friction consists in measuring the true area of bonding contact $A^{\prime}$ between two sliding bodies as well as the average tractive stress $\tau^{\prime}$ in that true area of contact. The ultimate experiment for such 
measurements has not yet been devised. In the meantime, a reasonable substitute for $A^{\prime}$ is the area of mutual interface $A$, defined as excluding regions of measurable separation. Likewise, in the place of $\tau^{\prime}$ is substituted $S$, the shear strength of the bond, on the ground that $\tau^{\prime}$ will be some constant fraction of $S$ depending on the mechanism of bond fracture. The sliding friction force $F$ is then proportional to the product of $A$ and $S$. Ordinarily, the value of $S$ cannot be taken as the shear strength of the materials of the sliding bodies. Most surfaces are covered by adsorbed gases or other interposing layers in which shearing takes place preferentially. Even without such layers shearing may take place at the original interface where the shear strength is likely to be different from that within either substrate.

As an alternate to the direct proof of adhesion in friction, some attention has been given to indirect proof or "circumstantial evidence". This paper is one such effort and it reports a correlation between the frictional behavior and two mochanical properties of six polymers. In particular, it emphasizes the identical nature of the effect of temperature and sliding speed on friction, and the effect of temperature and strain rate on shear modulus and shear strength data of the material.

Polymers are viscoelastic materials. The essential feature of such materials is that by raising the temperature, the same change in properties (e.g. elastic modulus) as by lowering the strain rate is obtained. Leaderman ${ }^{4}$ was the first to make use of this, and showed how data taken at one temperature over a range of strain rate $\dot{\gamma}$ can be superimposed on data taken at a different temperature merely by shifting the data curve along the horizontal strain rate axis. It was found by several investigators that the dependence of the above horizontal shift on temperature change follows the same law as the dependence of chemical reaction rate on temperalure change. The latter is expressed by an equation due to Arrhenius :

\section{Reaction rate $\propto \mathrm{e}^{-Q / R T}$}

where $T$ is the absolute temperature, $R$ is the universal gas constant and $Q$ is the activation energy of the reaction. The Arrhenius equation is inconvenient to use in some temperature ranges because $Q$ changes with temperature. In such cases, a special transform is used by the name of the W-L-F transform ${ }^{5}$. For the purpose of this work, the Arrhenius transform was found to be adequate.

For the shifting of mechanical property data, the Arrhenius equation is usually adapted as follows:

$$
\log \frac{\dot{\gamma}}{\dot{\gamma}_{0}}=\frac{Q}{R}\left(\frac{1}{T}-\frac{1}{T_{0}}\right)
$$

where $T_{0}$ is the first test temperature, $\dot{\gamma}_{0}$ is the strain rate of a reference point on the data curve, $T$ is the new temperature, and $\dot{\gamma}$ is the new position on the strain rate axis of the reference point of the data curve. The ratio $\dot{\gamma} / \dot{\gamma}_{0}$, or the ratio of equivalent rate processes, is usually designated $a_{T}$.

One of the interesting uses of viscoelastic transforms is to measure properties of material over a range of strain rate and temperature and then by transformation to predict behavior over many more decades of time or rate than it is possible to measure. There are limits to the applicability of the time-temperature superposition principle outlined above and study continues on this subject. Beyond the empirical 
development of the above concepts, Tobolsky ${ }^{6}$ and Ferry ${ }^{5}$ have developed a theoretical basis for the time-temperature transforms.

A viscoelastic effect was found in the sliding friction of rubber $\left(\mathrm{Grosch}^{2}\right)$. The results shown in Fig. 1 were taken from later work of Ludema and Tabor ${ }^{1}$, and they confirm Grosch's work. If the data curves are translated horizontally, they can all be made to overlap others and become segments of one continuous curve extending over a wide range of sliding speed. The latter is called the master curve. If the curve for

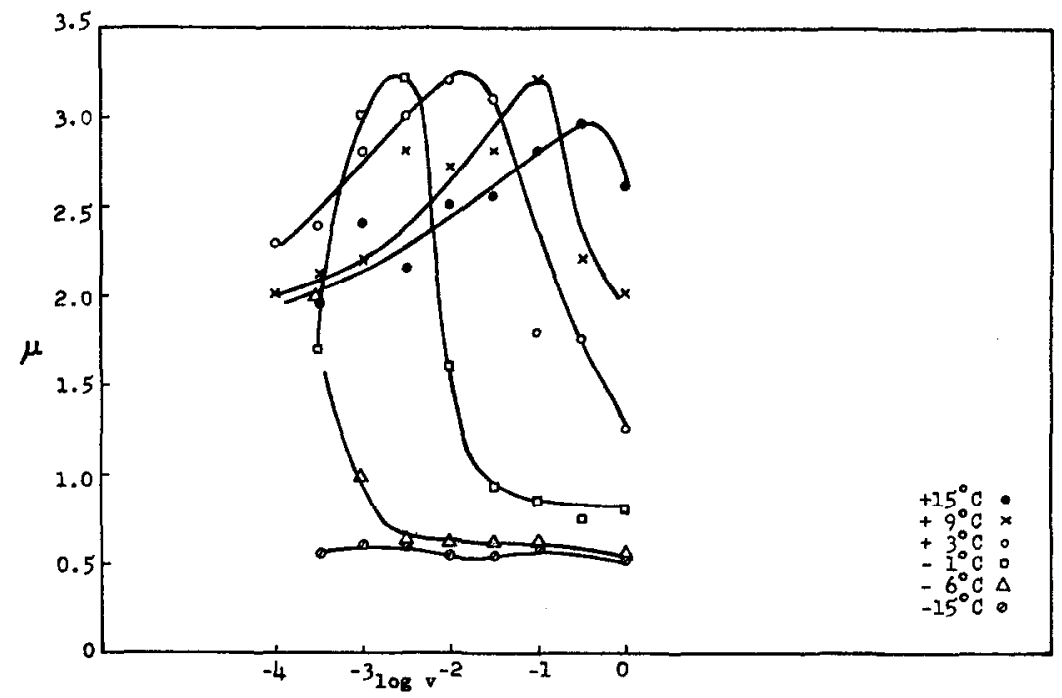

Fig. 1. Coefficient of friction vs. $\log$ velocity at various temperatures for acrylonitrile-butadiene rubber.

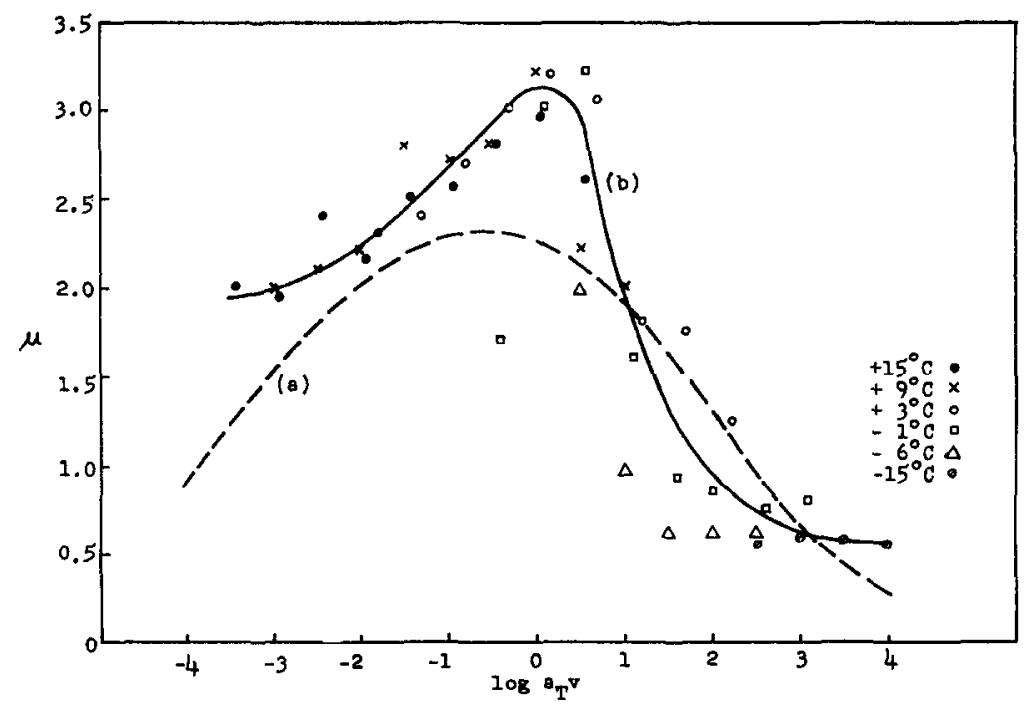

Fig. 2. Master curve at $20^{\circ} \mathrm{C}$ for acrylonitrile-butadiene rubber, (a) master curve by Grosch, (b) master curve by Ludema. 
$+15^{\circ} \mathrm{C}$ were arbitrarily selected to remain where it is, the $+9^{\circ} \mathrm{C}$ curve is translated to the right a small amount, the $+3^{\circ} \mathrm{C}$ curve is translated a larger amount, etc. The amount of translation increases as the temperature departs farther from $+15^{\circ} \mathrm{C}$ Figure 2 shows the transformed or master curve of the data of Ludema and Tabor in solid line, and the transformed curve of Grosch's data in broken line. These master curves were obtained by using the W-L-F transform.

Equations of the Arrhenius form may also express the above connection between temperature and horizontal shift:

$$
\log \left(\frac{V_{2}}{V_{1}}\right)=\frac{Q}{R}\left(\frac{1}{T_{2}}-\frac{1}{T_{1}}\right)
$$

where $V$ is the sliding speed. The important point here is that if a translation on the sliding speed axis follows the same form as translation of strain rate in mechanical tests, it would imply that increased sliding speed produces an increased strain rate in the materials. It would be even more convincing if the activation energy $Q$ were the same in both cases. Grosch made no attempt to show such a connection. On the other hand, he did report that $1 \mathrm{~cm} / \mathrm{sec}$ sliding speed of rubber on glass seemed to pioduce the same effect as a vibration of $10^{5}$ c.p.s. This would imply that there is a real vibration at sliding interfaces, but it must be the result of friction and not a cause.

The work of Ludema and Tabor was an attempt to extend the method of Grosch to plastics and to establish a more formal connection between sliding speed and strain rate in the polymer. It was confirmed in rubber that a spherical metal slider produced a strain cycle in the substrate, and sheared a thin film at the surface of the polymer. A sliding speed $V$ of $1 \mathrm{~cm} / \mathrm{sec}$ appeared to produce a shear strain rate in the surface film of $10^{6} / \mathrm{sec}$ and an average shear strain rate in the substrate of $10 / \mathrm{sec}$. The conclusions were less than satisfactory in the plastics because of the lack of good data for the mechanical properties of polymers. Therefore a new attempt was made which is now reported to correlate the frictional and mechanical properties of some polymers by showing identical response to viscoelastic variables. All material properties were measured using carefully controlled materials.

\section{THE RESEARCH OUTLINE}

The correlation of the frictional behavior of a material with its mechanical behavior involves several steps. It begins by selecting materials with large viscoelastic effects; that is, materials whose properties are strongly dependent on deformation rate and temperature. Then a friction model must be chosen and here it is assumed that the most applicable model is $F \propto A S$. It is necessary to express each variable as a viscoelastic function. The quantity $F$ can be obtained from a friction experiment using a constant load but a wide range of temperature and sliding speed. The experiment is conducted in such a way as to minimize all components of friction except the desired adhesion component and, in polymers, the inevitable deformation component. The latter is separated out by measuring friction under well-lubricated conditions while otherwise duplicating the conditions of the sliding friction test.

The quantity $S$ is taken to be proportional to $S_{\mathrm{s}}$, the shear strength of the polymer. This is perhaps the most tenuous a priori assumption in the work. However, $S$ 
cannot be measured, and ultimately the validity of the above assumption can be assessed by the nature of test results which are presented later. In this work, $S_{\mathrm{s}}$ was measured over a wide range of strain rate and temperature.

The quantity $A$ is assumed to be proportional to the Hertzian contact area $A_{\mathrm{h}}$. The latter is related to a number of factors. For a "rigid" sphere on a soft substrate, $A_{\mathrm{h}} \propto 1 / G^{2}$ where $G$ is the elastic shear modulus of the material, assuming the Poisson ratio of the material remains constant over all conditions of testing. The value of $A_{\mathrm{h}}$ can therefore be determined by measuring $G$. Conversely, $A$ may be approximated directly by experiment, and this quantity is called $A_{\mathrm{t}}$. Both methods were used to approximate $A . A_{\mathrm{t}}$ was found to differ from $A_{\mathrm{h}}$. The reason for the latter is that in a sliding friction test the contact stress conditions include a tractive stress, whereas the Hertzian equation for $A_{\mathrm{h}}$ is based on a normal load only upon the indentor.

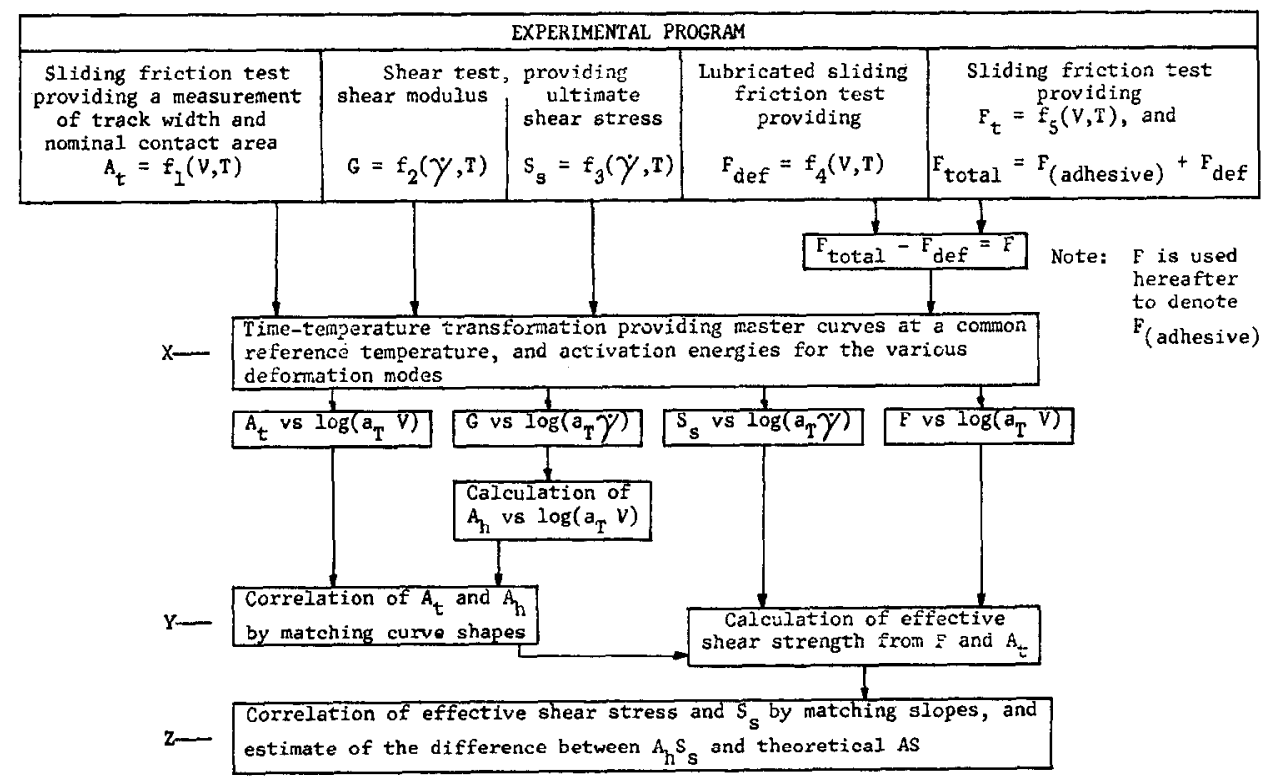

Fig. 3. The research outline.

The number of steps involved in this correlation study and the relationships between steps are shown in Fig. 3. The procedure was designed to progressively establish three major points. Experimental data are seen in Fig. 3 to enter step X where viscoelastic transformation or data curve translation is done. In this step, the activation energies $Q$ for each test are calculated using the Arrhenius equation. Similar values of $Q$ for each of the shear tests and the dry sliding friction tests would indicate that the physics of polymer molecular motion is the same in all tests, even though each material may have a different value of $Q$.

In step X, the data are put into form for later analysis. Transformed data $G$ vs. $\log \left(a_{T} V\right)$ is used to calculate $A_{\mathrm{h}} v$ s. $\log \left(a_{T} V\right)$, and the latter is compared with $A_{1} v$ s. $\log \left(a_{T} V\right)$ in step Y.

Step $\mathrm{Z}$ takes other transformed data from step $\mathrm{X}$. The friction force data are 
divided by an appropriate area of contact to get a calculated effective shear strength of polymer at the interface. The latter is compared with measured $S_{\mathrm{s}}$ by superposition of curves.

\section{THE EXPERIMENTS}

The materials selected were low and high density polyethylenes, atactic polypropylene, and three ethylene-propylene copolymers. Atactic polypropylene represented an amorphous material, low density polyethylene a medium crystallinity polymer, and high density polyethylene a high crystallinity polymer. The three grades of ethylene-propylene copolymers had varying proportion of the constituents, a feature likely to show the difference in the mechanical and frictional properties. The polymers are identified in more detail in Table I. Since commercial copolymer sheets contain SRF Black, oil, zinc oxide, sulfur and DiCup 40C, etc., research samples in the form of blocks were obtained and molded locally to make sheets.

TABLE I

IDENTIFICATION OF POLYMERS IESTED

\begin{tabular}{|c|c|c|c|c|}
\hline \multicolumn{2}{|l|}{ Polymer } & Density & Crystallinity & $\begin{array}{l}T_{g} \\
\left.\rho^{C} C\right)\end{array}$ \\
\hline \multirow{3}{*}{\multicolumn{2}{|c|}{$\begin{array}{l}\text { Linear (high density) polyethylene } \\
\text { Branched (low density) polyethylene } \\
\text { Atactic polypropylene }\end{array}$}} & $\sim 0.96$ & $>90 \%$ & -120 \\
\hline & & $\sim 0.92$ & $\sim 55 \%$ & -120 \\
\hline & & & $\sim 10 \%$ & -20 \\
\hline Copolymer grade & $\begin{array}{l}\text { Ethylene } \\
(\%)\end{array}$ & $\begin{array}{l}\text { Propylene } \\
(\%)\end{array}$ & Crystallinity & $\begin{array}{l}T_{g} \\
\left({ }^{\circ} \mathrm{C}\right)\end{array}$ \\
\hline Vistalon 3708 & 75 & $22 \star$ & $1-2 \%$ & -50 \\
\hline Vistalon 6505 & 60 & $31 \star$ & low & -45 \\
\hline Vistalon 404 & 40 & 60 & low & -55 \\
\hline
\end{tabular}

$\star$ Balance is unsaturated material.

In order to correlate frictional properties and shear properties, it was necessary to design the different experiments to cover corresponding states. A great number of constraints entered into the choice of the experimental parameters finally chosen. The actual range of parameters will be used in an illustration of corresponding states. In the friction tests for this work, the sliding speed range was from $2 \times 10^{-5}$ to $2 \times 10^{-1}$ $\mathrm{cm} / \mathrm{sec}$. This range is plotted on a scale of logarithmic rate in Fig. 4. Assuming that the rate of shear at the sliding interface is 6 orders of 10 higher on the rate axis, and the rate of shear in the substrate is 1 order of 10 higher on the rate axis, both are shown in Fig. 4 as corresponding ideal shear strain rates for the given sliding speed (rate) range. In the shear strength test, the actual range of shear rate is from 0.5 to $888 \mathrm{sec}^{-1}$, whereas for the shear modulus test the range is from 0.1 to $177 \mathrm{sec}^{-1}$. These ranges are also plotted in Fig. 4. The actual test ranges overlap only a small part of each of the ideal shear rates in Fig. 4, which therefore implies that the regimes of potential correlation of shear properties with frictional properties are limited. Furthermore, the correlative regime for the shear modulus data does not overlap the correlative regime for the 


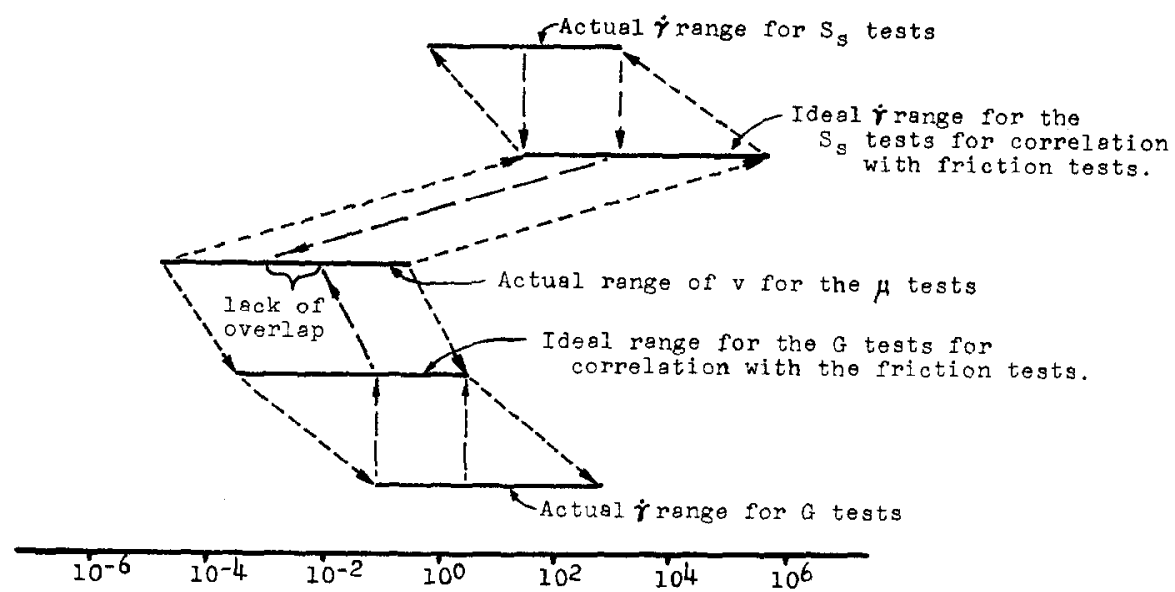

Fig. 4. The ranges of test conditions showing the correlative regimes at a single temperature.

shear strength data. Thus, much of the available data would be of no use.

Fortunately, the viscoelastic time-temperature transformation technique allows a broad view and makes possible a reasonable correlation. The illustration in Fig. 4 is for one temperature for all the tests. If tests were to be done over a range of temperature, it would have the effect of increasing the range of rate; i.e. sliding speed and shear strain rate. For example, if the temperature were varied from $-100^{\circ} \mathrm{C}$ to $-50^{\circ} \mathrm{C}$, it would have the effect of expanding the rate range by 6.5 orders of 10 (for $Q$ near $10 \mathrm{kcal} / \mathrm{mol}$ as found in this work). The "expanded" ranges on the rate axis are shown in Fig. 5; the degree of overlap is very great. Each of the shear tests can be well correlated with friction results and there is a large region where results from both shear tests can be correlated with the results from the friction test.
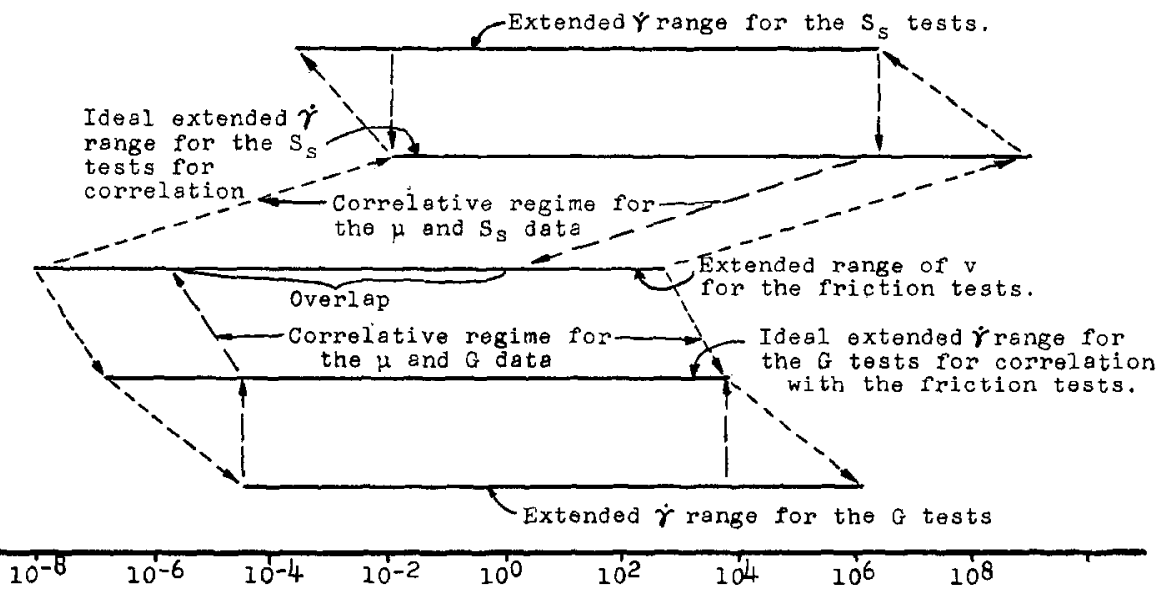

Fig. 5. The ranges of test conditions extended by visco-elastic transformation to achieve an overlap in correlative regimes. 
The above expansion of data range is based on the availability of a viscoelastic transform that is applicable over the entire range of test temperature. The simple transforms were found not to be applicable and therefore a new transform was developed. This will be discussed later.

\section{(a) The shear test}

The shear specimens were cut from $\frac{1}{8}$ in. thick sheet into the form shown in Fig. 6, a design based on the stress distribution studies of $\mathrm{Zapel}^{8}$, but modified to suit the wide temperature range of this work. Brittle fracture is a serious problem at low temperatures, whereas large strains and specimen distortion is the chief difficulty at high temperature.

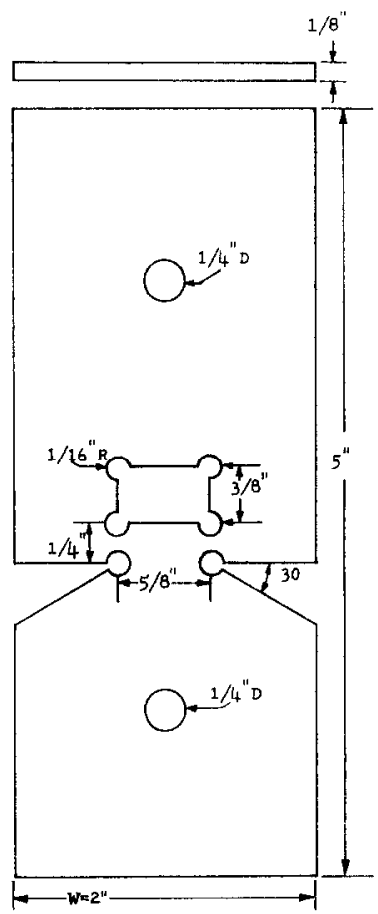

Fig. 6. Dimensions of double shear specimen.

The specimen was pulled in a tensile device with a linear velocity range of 4.5 in./min to $7065 \mathrm{in}$./min. The measured strain rate range for the shear modulus test was from 0.1 to $178 \mathrm{sec}^{-1}$ and for the shear strength test from 0.5 to $888 \mathrm{sec}^{-1}$. The tensile device was equipped with a strain gage transducer. The output from the transducer was recorded on a memory oscilloscope and then photographed for later analysis.

For cooling the specimens a cooling tower was designed. It consists of 56 slots each $2 \frac{3}{8}$ in. $\times \frac{1}{4}$ in. $\times 6$ in., obtained by machining slots in two aluminium solid blocks, and assembling them with the cut slots facing each other. The slotted blocks are supported to stand vertically with a heater attached to the bottom and a liquid 
nitrogen reservoir on the top. A temperature range of $-170^{\circ}$ to $10^{\circ} \mathrm{C}$ could be achieved but the full range was seldom used.

\section{(b) The friction tests}

The basic configuration of specimens for the friction test is the rigid sphere sliding on the flat polymer disc of $3 \mathrm{in}$. diam. The disc can be rotated at speeds ranging from $10^{-5}$ r.p.m. to 625 r.p.m. The rigid sphere is attached to a cantilever transducer which provides a measure of the friction force. The normal load on the rigid sphere is a dead load, usually of $875 \mathrm{~g}$.

Specimen temperature is controlled by a combination of the circulation of liquid nitrogen and controlled electric heaters. Temperature accuracy of better than $1^{\circ} \mathrm{C}$ could be maintained automatically.

For low temperature friction work, it is necessary to prevent the condensation and freezing of water on specimen surfaces. It is possible to conduct the experiments in a dry atmosphere, but it is difficult to ensure dryness, therefore the work was done in a vacuum, usually one order of ten better than the vapor pressure of water at the desired test temperature. An oil diffusion pump was used together with a vapor trap cooled by liquid nitrogen.

Figure 7 shows the friction measuring apparatus. The working area is in the heavy vacuum chamber under a glass cover. Manipulators are used for applying the normal load, for applying a calibrating force to the friction force measuring transducer, and for changing the radial position of the slider on the disc of polymer to enable testing on a fresh or ungrooved surface without the need for changing specimens. A Honeywell Visicorder records a number of variables including friction force.

The measurement of track area was done separately, but under nearly the same conditions as the friction force measurements. To aid in accurate track width measurements, it was found convenient to vapor-deposit a thin film of aluminum on the polymer surface. With experience, a film thickness was found that aided the measurement without changing the friction force from that found for a clean polymer surface.

The deformation component of friction force was measured by lubricating the friction interface with a silicone fluid. It was found in every case to be small as compared with the variations in total friction. The exercise of subtracting the deformation component from total friction was therefore not done.

The friction specimens were prepared in the following manner. The spherical sliders were made of brass, lapped, cleaned with liquid detergent and rinsed in isopropyl alchol. The polyethylene and polypropylene specimens were rubbed on 600 grade abrasive cloth under running water, cleaned in liquid detergent and rinsed in isopropyl alcohol. The ethylene-propylene copolymers were too soft to be rubbed on abrasive cloth; they were moulded against glass, washed in liquid detergent, and sprayed with isopropyl alcohol.

A problem in friction testing is the large variation in friction often seen over a specimen surface, or between specimens. Such variations can be minimized by a rigorous procedure of cleaning and handling. Some variation is unavoidable, so all specimens were checked and regions on the specimen that produced questionable results were avoided throughout later testing. Where particularly reliable data were needed for correlation, the friction force at speeds near $10^{-2} \mathrm{in} . / \mathrm{sec}$ were taken. 


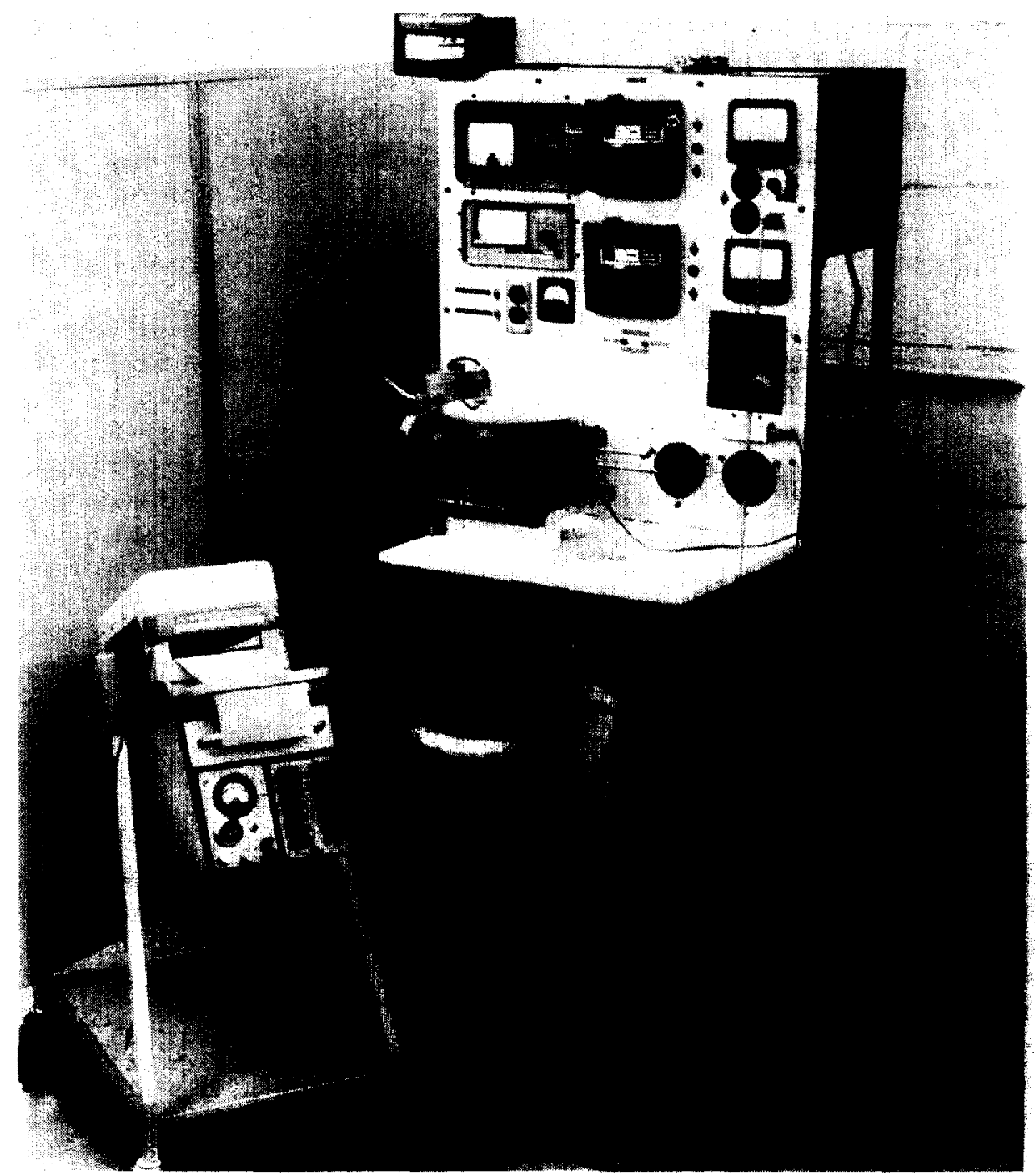

Fig. 7. The friction test set-up.

4. THE DATA

As is seen in Fig. 3, all the experimental data were transformed in accord with the time-temperature superposition principle. It was necessary to develop special transforms to account for changes that occur in the polymers over a wide temperature range. The theoretical basis for the new transforms and the details of the use of the transforms are published elsewhere ${ }^{9}$. Since only the transformed shear stress data are of interest in a correlation with friction, the original data from the shear tests are left with the companion paper and not repeated here. However, original dry sliding friction data and all transformed curves for both the friction and shear properties are given in this paper. Figures 8 to 13 show original data for the friction tests of the six polymers. 


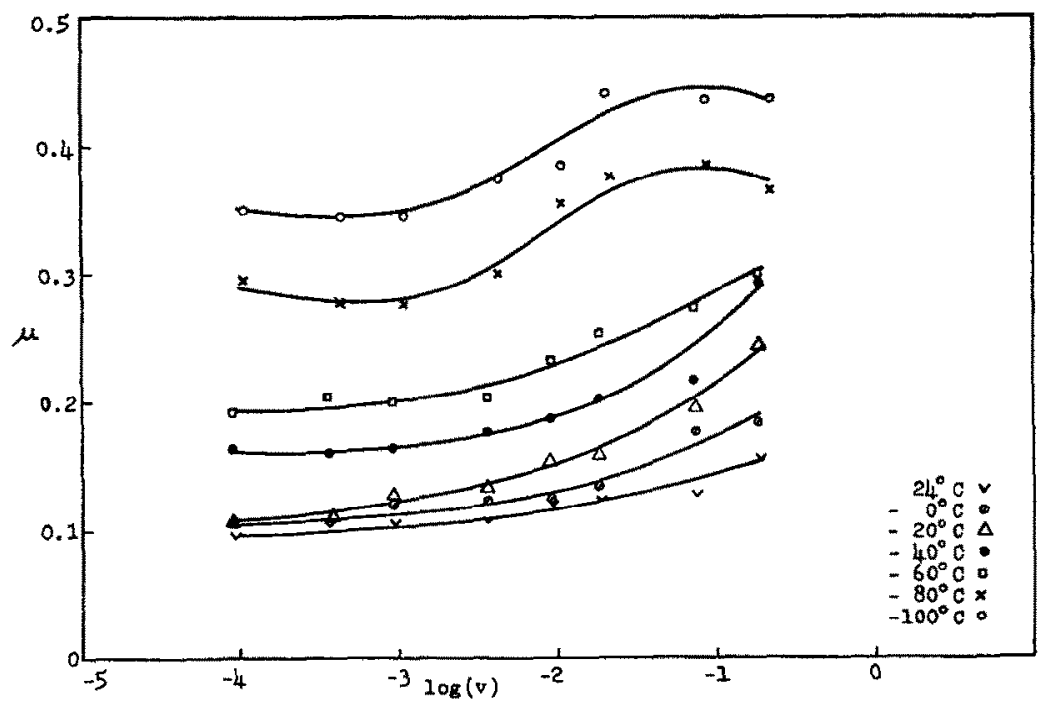

Fig. 8. Coefficient of friction vs. $\log$ velocity at various temperatures for linear PE.

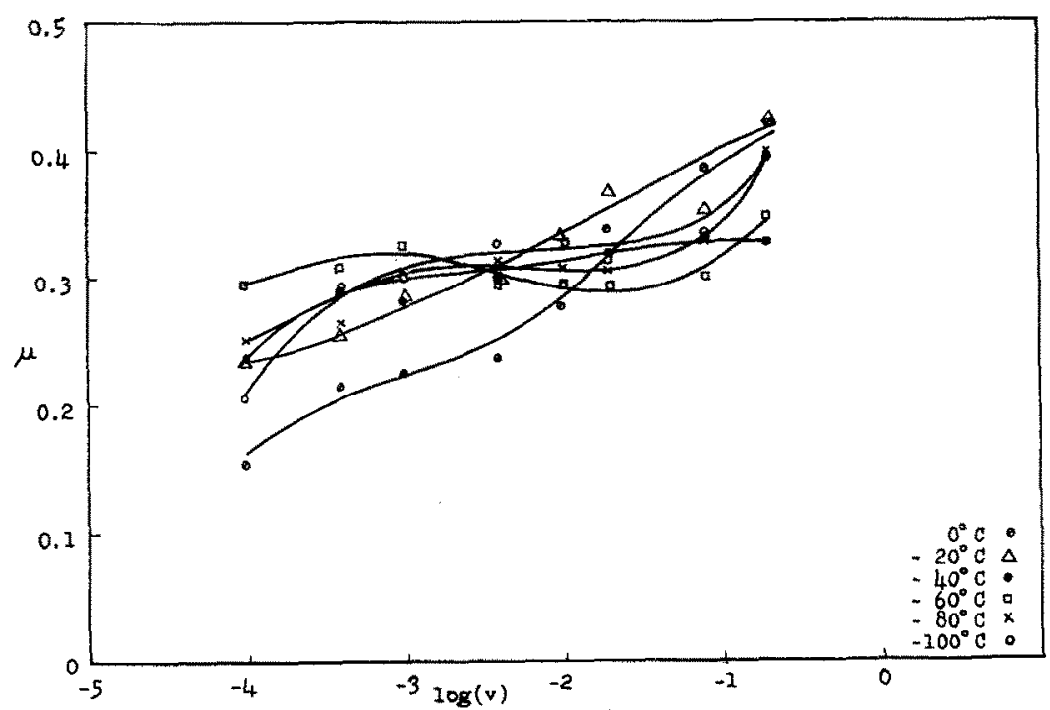

Fig. 9. Coefficient of friction vs. $\log$ velocity at various temperatures for branched PE.

Figures 14 and 15 are typical master curves derived by transformation of the curves in Figs. 8 and 13.

\section{(a) The transforms}

The success of the ordinary time-temperature transformation techniques is sometimes limited by changes in the morphology of a polymer. There are a number of changes in morphology with temperature, called transitions. For example, beginning at a high temperature in the liquid phase, the molecular chains are in the form of interpenetrating random coils wriggling rapidly from one conformation to another. 


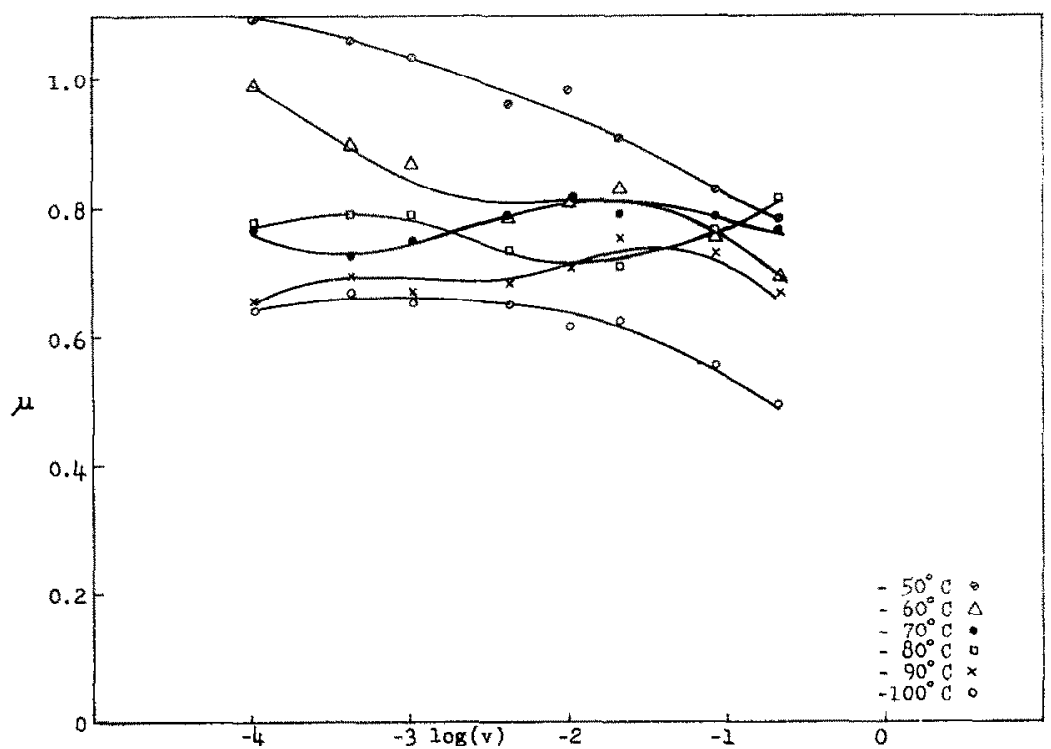

Fig. 10. Coefficient of friction vs. log velocity at various temperatures for Vistalon 3708 .

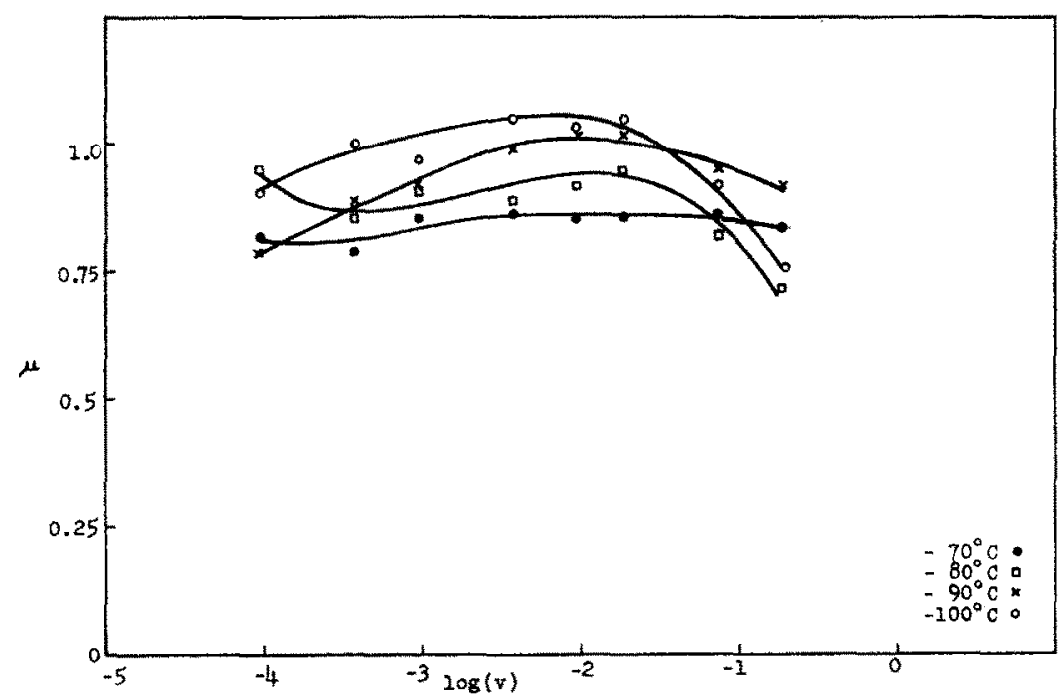

Fig. 11. Coefficient of friction vs. $\log$ velocity at various temperatures for Vistalon 6505 .

When a liquid polymer is cooled, two major events take place. At a particular temperature defined as the melting point (M.P.), some regions in the polymer undergo a large reduction in specific volume, and a crystalline structure results. The remaining non-crystalline regions are said to be amorphous. At a certain temperature, usually much lower than the melting point, the mobility of the molecular chains in the amorphous state is much reduced. The amorphous regions change in behavior from a rubbery state to a glassy state. The temperature of this change is called the glass transition temperature $T_{\mathrm{g}}$. Values of $T_{\mathrm{g}}$ are given in Table I. 
Most polymers are partially crystalline and partially amorphous. While there is no rigid definition, those polymers which tend to retain somewhat more than half of the amorphous phase are called amorphous polymers, etc. The usual degree of crystallinity at room temperature for the materials used in this test are given in Table I.

The experimental work was done over temperature ranges that encompass some changes in morphology of the polymer. Furthermore, there are changes in morphology that occur when an amorphous phase is strained, such as under a friction slider or in the shear strength test. These changes will affect the interchangeability of temperature and deformation rate as well as the effect of temperature and strain rate

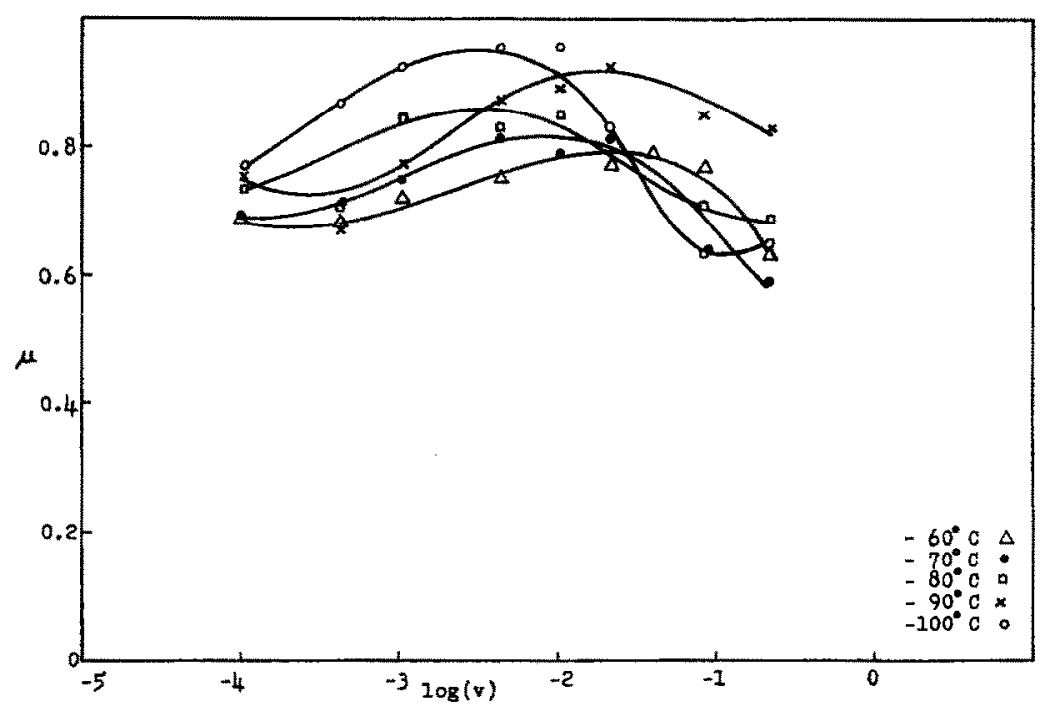

Fig. 12. Coefficient of friction vs. log velocity at various temperatures for Vistalon 404.

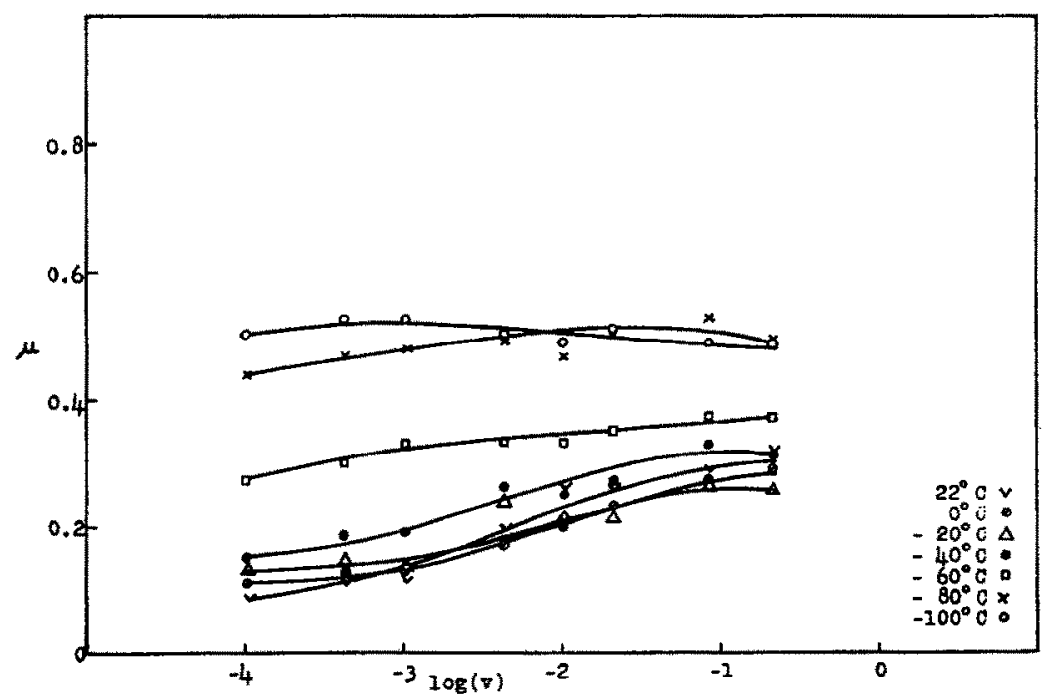

Fig. 13. Coefficient of friction vs. log velocity at various temperatures for Atactic PP. 
on mechanical properties of a polymer, and make it impossible to effect a simple transformation or horizontal translation of data as shown in Fig. 2(b).

However, changes in morphology produce an effect on vertical translation of data which is regular, and directly connected with the effect of morphology change on horizontal translation. Bueche ${ }^{10}$ and later Marvin ${ }^{11}$ developed a theory based on the existence of transient cross-links, and therefore the effective length of chain between cross-links. By this theory, a change in the number of network cross-links per unit volume by a factor $f$ will produce a change in the magnitude of mechanical properties by the same factor and a change in location on the strain rate (or sliding speed) scale of $f^{-\frac{1}{2}}$.

The application of the network density factor $f$ to the transformation of data may now be described. For convenience, the original data were replotted on logarithmic coordinates. The single curve which from the friction test appeared to be the most reliable was chosen as the base or reference for the master curve, and the temperature of that curve is called the reference temperature. The reference curve was replotted on tracing paper and laid over the remaining data curves. By a process of trial and error, the amount of vertical and horizontal movement required to bring the reference curve into coincidence with other curves was recorded. A vertical translation by the ratio $f$ was made to be compatible with the value of $f$ in the corresponding horizontal translation in the amount of $a_{T} f^{\frac{1}{2}}$. This was done by constraining the value of $a_{T} f^{\frac{1}{2}}$ for every set of two data curves for temperature $T_{1}$ and $T_{2}$ to produce a straight line on a plot of $\log \left(a_{T} f^{\frac{1}{2}}\right) v s$. $\left[\left(1 / T_{1}\right)-\left(1 / T_{2}\right)\right]$, where $T_{2}>T_{1}$, and by repeating the process

TABLE II

VERTICAL SHIFT FACTOR $f$, ACTIVATION ENERGY $Q(\mathrm{kCal} / \mathrm{mol})$ AND REFERENCE TEMPERATURES USED IN TRANSFORMATION OF DATA

\begin{tabular}{|c|c|c|c|c|c|c|c|}
\hline \multirow[t]{2}{*}{ Material } & \multirow[t]{2}{*}{$\begin{array}{l}\text { Reference } \\
\text { temp. }\left({ }^{\circ} \mathrm{C}\right)\end{array}$} & \multicolumn{2}{|c|}{$\begin{array}{l}\text { Friction test } \\
\text { (Fig. 18) }\end{array}$} & \multicolumn{2}{|c|}{$\begin{array}{l}\text { Shear } \\
\text { modulus test } \\
\text { (Fig. 16) }\end{array}$} & \multicolumn{2}{|c|}{$\begin{array}{l}\text { Shear } \\
\text { strength test } \\
\text { (Fig. 17) }\end{array}$} \\
\hline & & $f$ & $Q$ & $f$ & $Q$ & $f$ & $Q$ \\
\hline Linear PE & -20 & 1 & 12.2 & 1 & 10.1 & 1 & 9.3 \\
\hline Branched PE & -30 & 1 & 9.52 & 1 & 12.3 & 1 & 12.4 \\
\hline Atactic PP & -40 & 1 & 9.9 & 1 & 8.3 & 1.25 & 8.9 \\
\hline Vistalon 3708 & -50 & 1 & 10.8 & 1.35 & 11.1 & 1.25 & 10.1 \\
\hline Vistalon 6505 & -70 & 1 & 8.6 & 1 & 7.1 & 1.2 & 9.2 \\
\hline Vistalon 404 & -70 & 1 & 8.0 & 1.16 & 8.7 & 1.35 & 11.7 \\
\hline
\end{tabular}

for $\log a_{T}$ vs. $\left[\left(1 / T_{1}\right)-\left(1 / T_{2}\right)\right]$. From the latter plot, the value of activation energy $Q$ could be obtained. Table II shows the value of $f, Q$ and reference temperature for the shear tests and the friction experiments.

(b) The transformed data

The friction results for linear polyethylene and atactic polypropylene taken from Figs. 8 and 13 were transformed by the method described above, and are shown in Figs. 14 and 15. The latter curves provide a broad spectrum of the frictional behavior of these polymers "at the same temperature" over more orders of ten velocity 


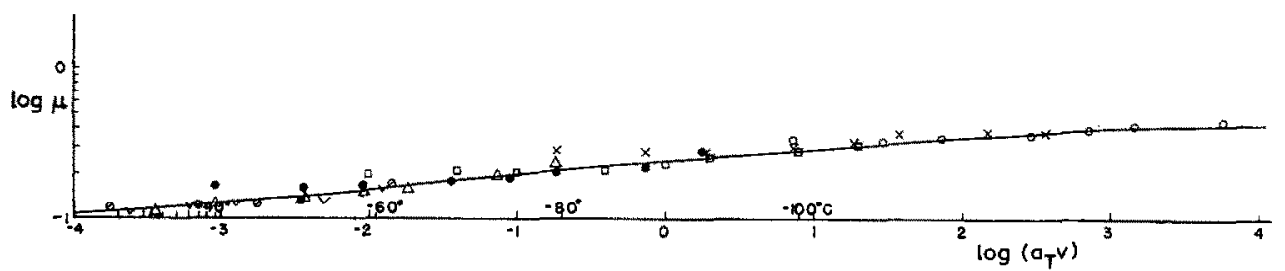

Fig. 14. Master curve at $-20^{\circ} \mathrm{C}$ for linear PE.

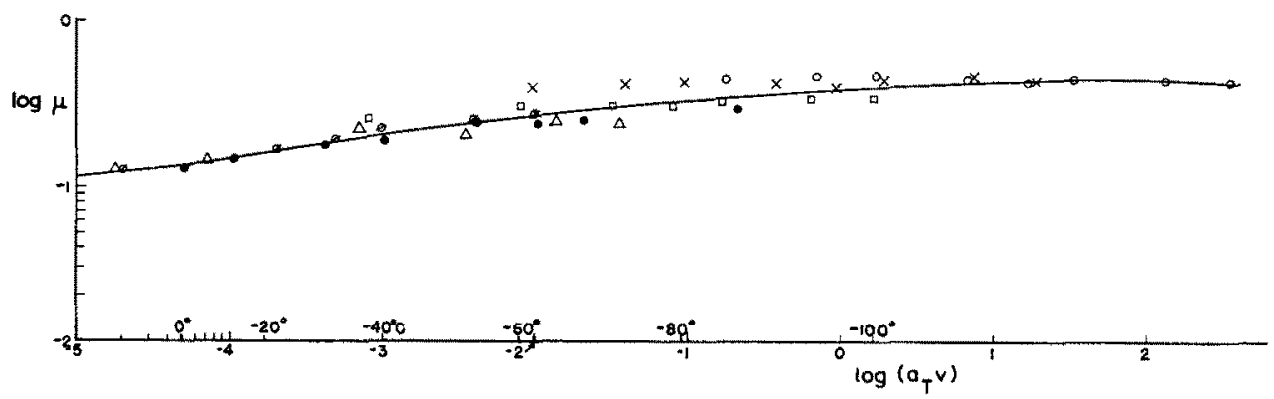

Fig. 15. Master curve at $-40^{\circ} \mathrm{C}$ for Atactic PP.

range than is available by experiment. The location of the original data on the master curve is indicated in the figures. For example, the data taken at $-100^{\circ} \mathrm{C}$ are found to the right of the number " $-100^{\circ} \mathrm{C}$ " below the master curve.

Scatter of data around the master curve is a consequence of inhomogeneity in material, errors in experimental measurements and inadequacy in the transformation procedure. Friction results are rather sensitive to inhomogeneity in material and it was found that transformed friction data have more scatter than transformed shear data. All the transformed data points for shear modulus fall within a range of $\pm 7 \%$ of the plotted master curve. Some $90 \%$ of the shear strength data points also fall within $\pm 7 \%$ of the master curve. On the other hand, the friction data fall within $\pm 12 \%$ of the friction master curves.

The scatter in data compares favorably with similar work reported in the literature. Smith ${ }^{12}$ found a scatter of $5-7 \%$ for transformed tensile strength data for a rubber. Lohr ${ }^{13}$ found a total scatter of about $25 \%$ in his transformed yield strength data for a polymethylmethacrylate. The state of affairs in transformed friction data in the literature is far worse. Bueche and Flom ${ }^{1}$, Grosch ${ }^{2}$, and Ludema and Tabor ${ }^{7}$ report scatter in excess of $25 \%$ and sometimes approaching $100 \%$. By comparison, the transformed curves reported in this paper must be regarded as an advance in the state of viscoelastic transforms of data not otherwise considered transformable.

All the transformed shear test data and dry sliding friction test data are shown in Figs. 16, 17, and 18. From Table II it can be seen that, for each material, the value of $Q$ for each of the three tests is reasonably similar. The greatest difference exists for materials with very flat data curves. Such curves are difficult to transform accurately. For these materials a large disparity in values of $Q$ must he regarded as indicating the degree of difficulty in transforming data. For other materials, the closeness of values of $Q$ indicates that nearly the same molecular mechanisms are taking place under a friction slider as in a shear test.

The track width produced by a slider on the polymer surface was measured 

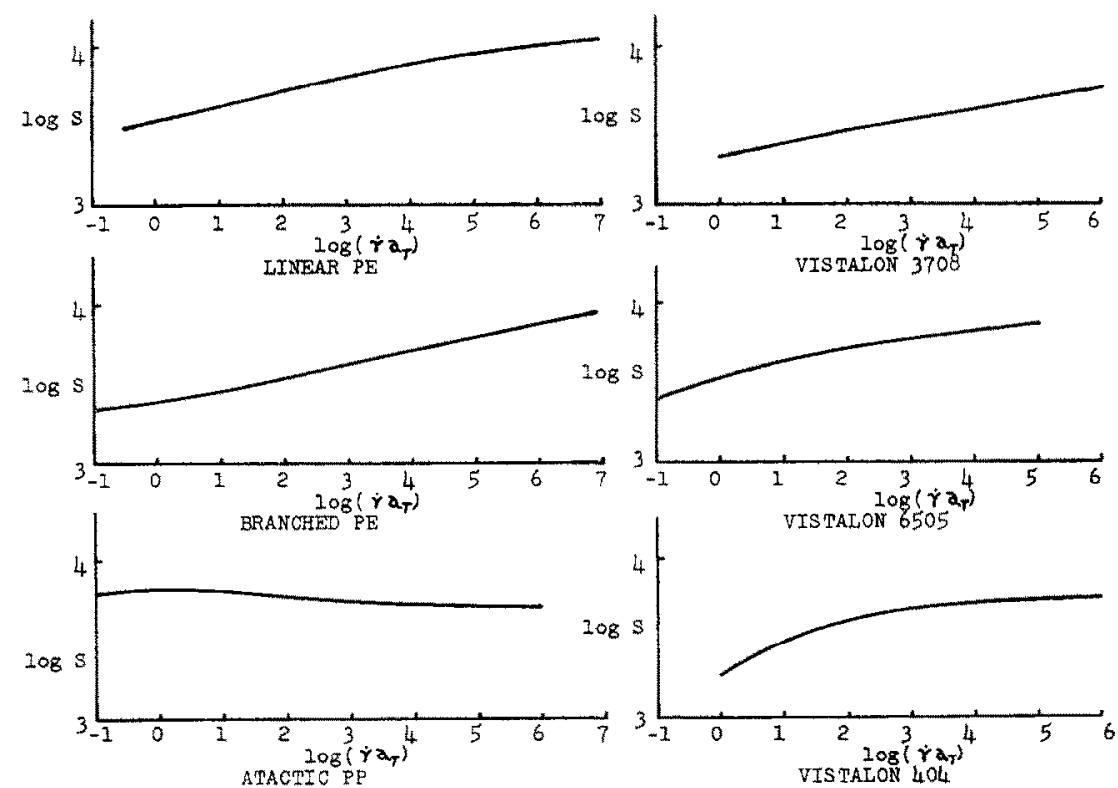

Fig. 16. Shear strength master curves for the test polymers.
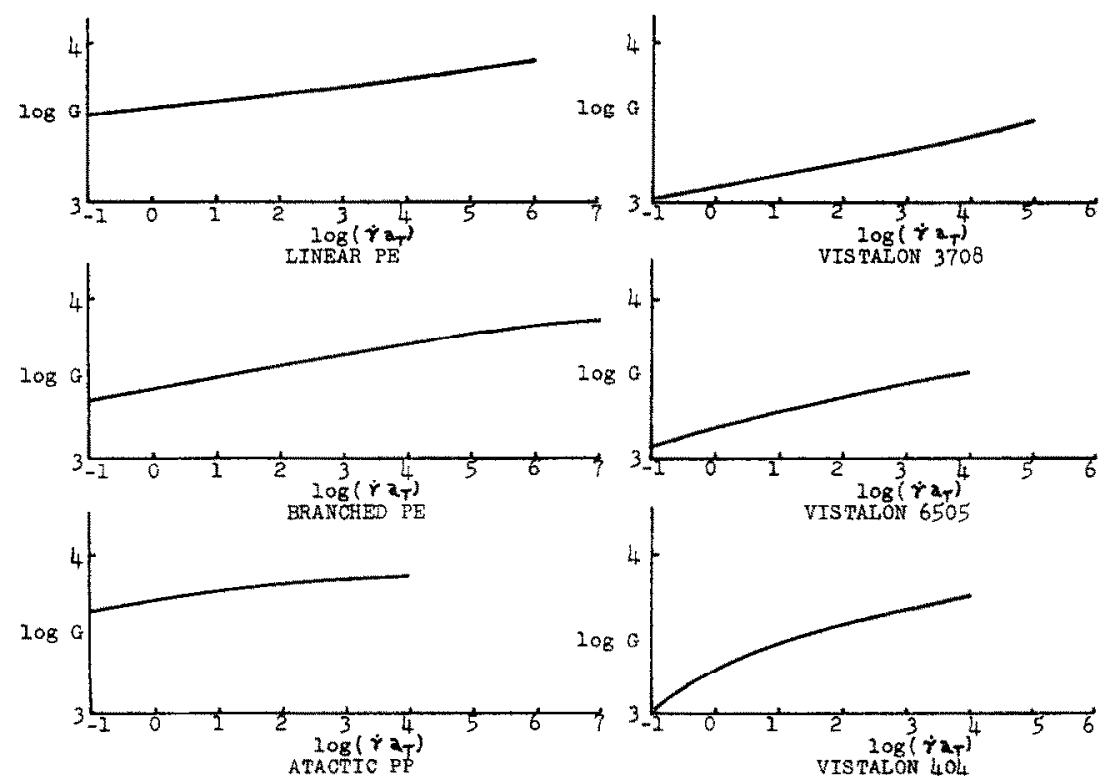

Fig. 17. Shear modulus master curves for the test polymers.

for a number of temperatures at a sliding speed of $2 \times 10^{-2} \mathrm{in}$./sec. On the assumption that the frictional contact area was circular, a value of contact area $A_{\mathrm{t}}$ was calculated from the track width. The data for $A_{\mathrm{t}}$ were transformed using values of $Q$ from sliding friction tests, and the master curves are shown in Figure 19. The scatter of data points around the master curve in this case was less than $\pm 2 \%$. 

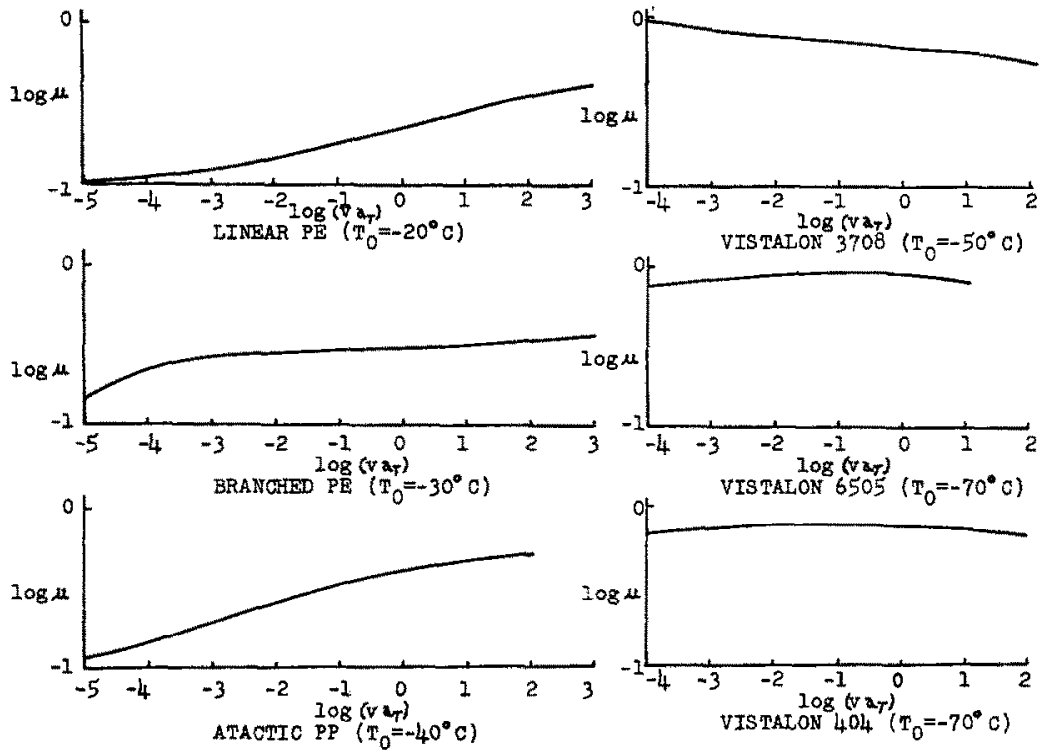

Fig. 18. Coefficient of friction master curves for the test polymers.
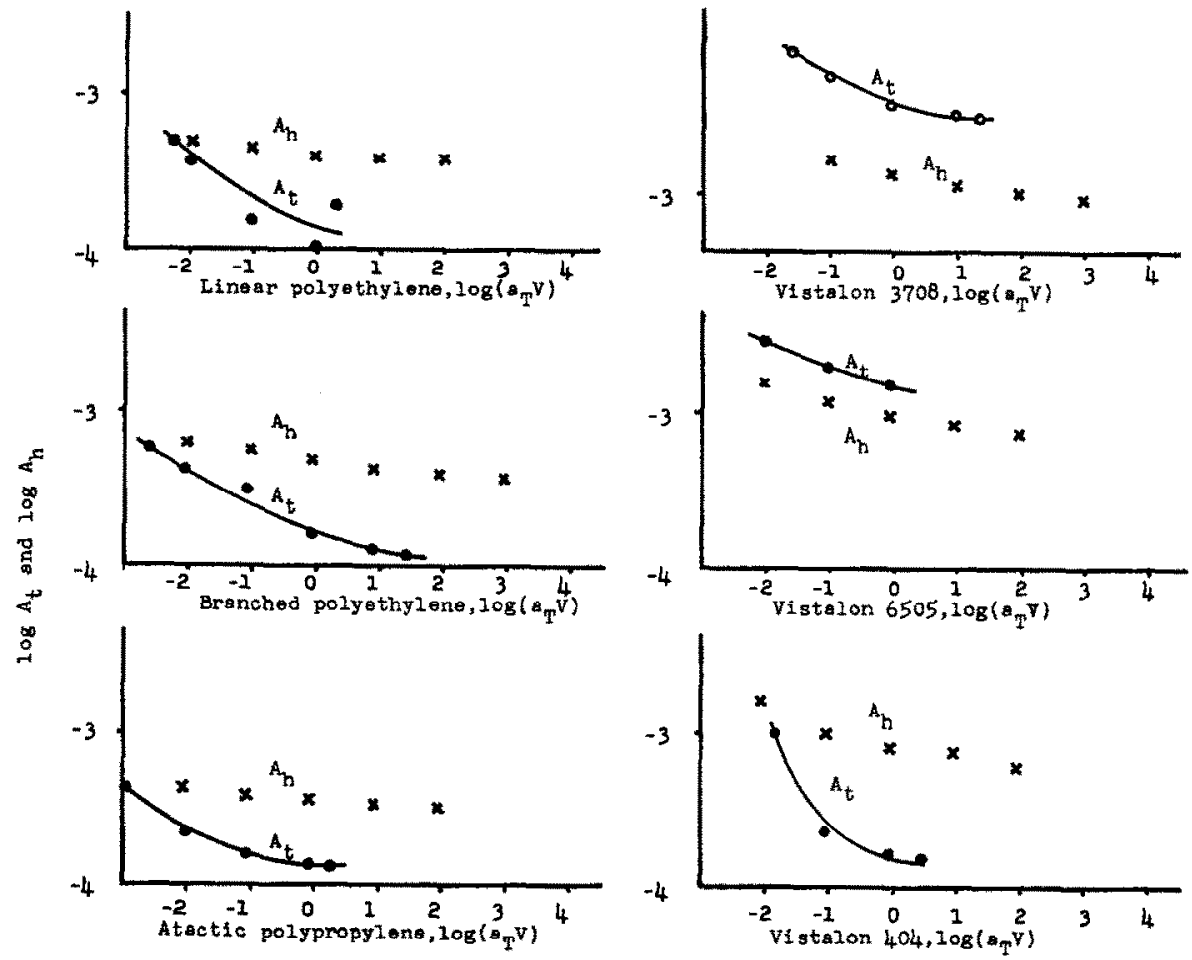

Fig. 19. Track area $A_{\mathrm{t}} v$ s. sliding velocity with calculated points of $A_{\mathrm{h}}$. 


\section{THE CORRELATION}

(a) Area of contact

In the research outline, it can be seen that it is necessary to correlate measured area of slider contact $A_{\mathrm{t}}$ with the area of contact $A_{\mathrm{h}}$ as calculated by the equation of Hertz from measured values of shear modulus. From standard textbooks, we find that

$$
A_{\mathrm{h}}=\pi\left[\frac{3 W r(1-\rho)}{8 G}\right]^{\frac{2}{3}}
$$

where $W$ is the load applied to a spherical indentor of radius $r$ and $\rho$ is the Poisson ratio of the indented material. For this work we may use $\rho=0.33$ (Schwarzl ${ }^{14}$ ) for the polypropylene and the copolymers, since at the temperature of the tests the materials were in the glassy state. For the polyethylenes $\rho$ was measured to be in the vicinity of $0.38-0.40$.

Values of $A_{\mathrm{h}}$ were calculated from master curves for $G$ and plotted in Fig. 19 as points, taking care to account for the assumed relationship that $1 \mathrm{~cm} / \mathrm{sec}$ sliding speed strains the substrate at $10 / \mathrm{sec}$. It is to be noted that all values of $A_{\mathrm{h}}$ are above the curves for $A_{\mathrm{t}}$. This probably arises mostly from the manner in which $G$ was measured. It was not taken as the initial slope of the stress-strain diagram but as the slope of a line from the origin of the stress-strain diagram to the end of the gradual curvature of the low strain region. The latter gives lower values of $G$ than the former, and therefore larger values of $A_{\mathrm{h}}$. An intensive study was made with linear polyethylene, taking the shear modulus to be the initial slope of the shear stress--strain diagram. This appeared to give a better fit between $A_{\mathrm{t}}$ and $A_{\mathrm{h}}$, although the mechanics are not well resolved. Studies on indentation in metals ${ }^{15}$ indicate that the amount of strain under an indentor ranged from about $10 \%$ near the indentor to zero at a great distance away. The implication would be that identation would be controlled by strain events somewhere between zero and $10 \%$ strain. The shear modulus taken at the origin of the stress-strain curve should therefore not be as applicable as some other value. More theoretical work is needed in this area.

Of more importance to this study than matching of absolute values of $A_{\mathrm{h}}$ and $A_{\mathrm{t}}$ is the fact that curves for $A_{\mathrm{h}}$ and $A_{\mathrm{t}}$ are of the same shape and orientation. This indicates a similarity of behavior of materials at low strain in a shear test and of the same material under a sliding sphere. In other words, it encourages the belief that the track width formed by a slider is controlled by the dynamic shear modulus $G$.

\section{(b) Friction force and shear strength}

To complete the correlation, the variation in effective shear strength at the sliding interface with variations in temperature and shear rate was calculated using the friction force and area of contact, and is shown in Fig. 20 for the corresponding states of all of the materials. The master curves for area of contact $A_{\mathrm{t}}$ and friction force $F$ were used, and therefore the curve for the calculated effective shear strength, $S_{\mathrm{f}}$, is also a "master curve". For comparison, the master curves for measured shear strength, $S_{\mathrm{s}}$, are also shown in Fig. 20. As seen previously, the calculated and measured values do not coincide. However, it is obvious that the form of curves compares very well. Had the form of the curves for $A_{\mathrm{h}}$ and $A_{\mathrm{t}}$ not coincided, there would be little 


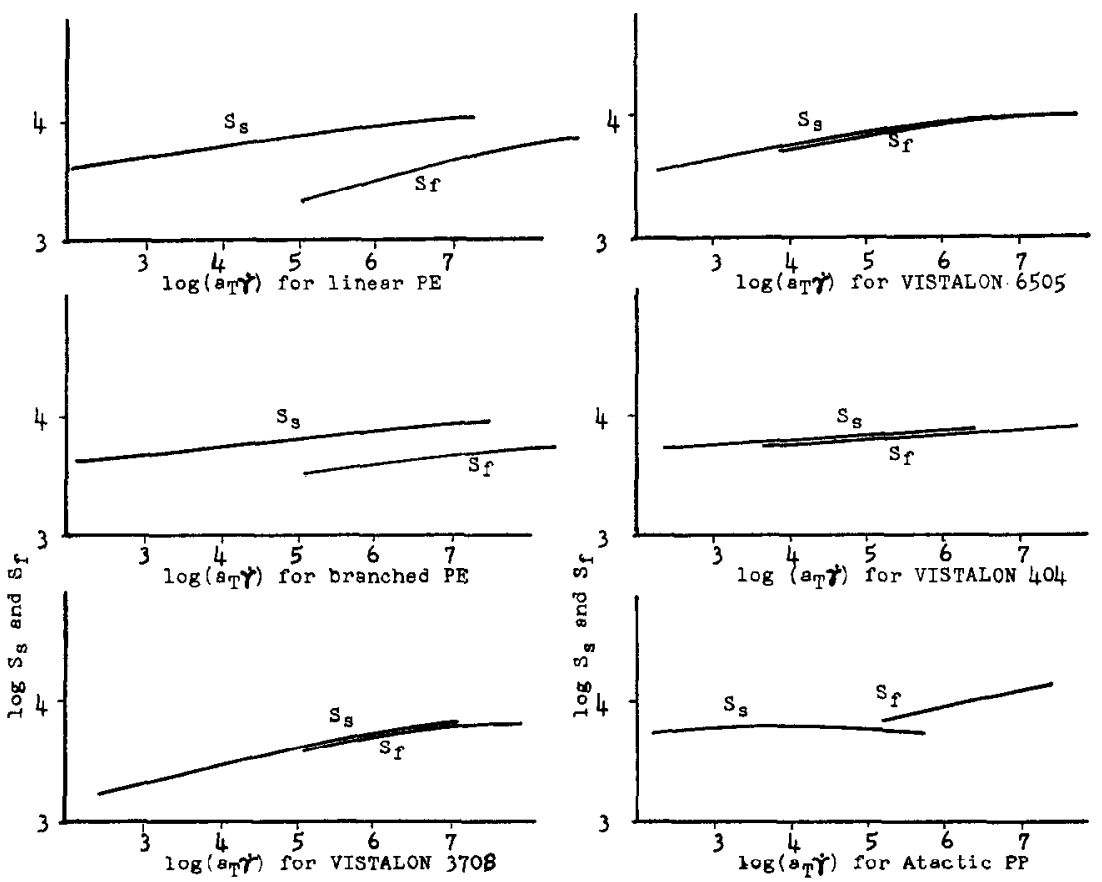

Fig. 20. Master curves of the measured shear strength $S_{\mathrm{s}}$ and effective shear strength $S_{\mathrm{f}}$ calculated from friction data. The curves are shifted horizontally in accord with the assumption that $1 \mathrm{~cm} / \mathrm{sec}$ sliding speed shears the surface film of the polymer at a rate of $10^{6} / \mathrm{sec}$.

hope of the curves for $S_{\mathrm{s}}$ and calculated shear strength, $S_{\mathrm{f}}$, coinciding. The fact that the curves in Fig. 20 do match in shape strongly supports the view that sliding friction does in fact involve shearing, probably very near to the polymer surface. This observation together with the observations relative to $A_{\mathrm{t}}$ and $A_{\mathrm{h}}$ in the previous section form the main thrust of this work. Friction forces for a hard slider on polymers are controlled by two separable mechanisms, by shearing near the interface and by the deformation properties in the polymer substrate. Furthermore, the changes in material properties with temperature and strain rate produce regular and separable changes in tractive stresses and tractive area at the interface of the sliding pair.

\section{DISCUSSION}

The work reported is an indirect proof of the adhesion theory of friction, in spite of the obvious deficiencies in correlating the absolute values of measured quantities. As mentioned in the introduction, the friction force is $F=A^{\prime} \tau^{\prime}$. Since the value of $A^{\prime}$ has not yet been measured, another quantity, $A$, is taken as a reasonable substitute. In the discussion of the correlation of $A_{\mathrm{h}}$ and $A_{\mathrm{t}}$, it is also obvious that the value of $A$ is far from settled. In addition, it can be easily shown that where a slider leaves an indented track in a softer substance, there is not full contact in the rear half of an imagined circle of contact.

The very indefinite value of $A$ was then taken in conjunction with $F$ to calculate an effective shear stress by way of $F / A$. The mismatch in absolute values, effective 
shear stress, and $S_{\mathrm{s}}$ now reflects two uncertainties, that due to $A$ and due to $F$, which is connected with $\tau^{\prime}$, a quantity not measured.

It might be interesting to measure $A$ more accurately in order to determine $k$ in the equation $F=k A s$. Unfortunately, the value of $k$ is likely to be different with every material, particularly the commercial grades of the polymers. For example, in Fig. 20 it can be seen that the values of $S_{\mathrm{f}}$ and $S_{\mathrm{s}}$ are rather close for the research grade of copolymers. On the other hand, the difference is large for the polyethylenes which are commercial grade materials. The reason may be connected with the presence of plasticizer in the commercial materials. Plasticizers influence bulk properties of a polymer to some extent, but plasticizers may exude from the surface of a polymer and smear over the surface to strongly influence $F$. This effect can be suspected when two pieces of a particular generic polymer from different sources have identical mechanical properties, but very different absolute values of $F$.

The assumed connection between sliding speed and shear strain rate in the material under the slider has not received support, as such a connection would require a nearly perfect match of absolute values of all the quantities. To ensure a good match of curves, there should be some distinguishing feature in the master curves such as a peak or other discontinuity. Most of the master curves reported here were monotonic with relatively small slope. Thus, no attempt was made to connect sliding speed with strain rate in the polymer.

Proof for the adhesion theory of friction is fraught with many difficulties. Such difficulties, as are found in this work cannot be used to discredit the theory in any way. On the other hand, the difficulties will delay the proof of the theory. However, the adhesion theory of friction has aged more gracefully than other theories and will probably continue to do so.

\section{ACKNOWLEDGEMENTS}

We wish to acknowledge the support which we received in this work, from the National Science Foundation in the form of a grant, and the Enjay Chemical Company for the special grade of Vistalon.

\section{REFERENCES}

1 A. M. Bueche AND D. G. Flom, Wear, 2 (1958-59) 168.

2. K. A. Grosch, Proc. Roy. Sor, A274 (1963) 21

3 F. P. Bowden AND D. TABOR. The Friction and Lubrication of Solids, Clarendon Press, Oxford, 1964.

4 H. LEADERMAN, Textile Res. J., $1 /$ (1941) 171.

5 J. D. FERrY, Viscoelastic Properties of Polymers, Wiley, New York, 1961.

6 A. V. TOBOLSKY, Properties and Structure of Polymers, Wiley, New York, 1960.

7 K. C. LUdema AND D. TABOR, Wear, 9 (1966) 329.

8 E. J. ZAPEL, Symp. on Shear and Torsion Testing, ASTM Spec. Tech. Publ., 289 (1961) 26.

9 S. BADAhUR AND K. C. Ludema, High speed shear properties and master curves for ethylene-propylene copolymer system, J. Polymer Sci., in press, 1971.

10 F. Bueche, J. Appl. Phys., 26 (1955) 738.

11 R. S. MARVIN, in I. T. BrRGrN (ed.), Viscoelasticity-Phenomenological Aspects, Academic Press, New York, 1960.

12 T. L. Sмiтн, J. Polymer Sci., 32 (1958) 99.

13 J. J. LoHR, Trans. Soc. Rheol., 9 (1) (1965) 65.

14 F. SCHWARZL, Kolloid, 2, 148 (1956) 47.

15 D. TABOR, The Hardness of Metal, Oxford University Press, London, 1951 